\title{
Green User Electronics Lifecycle Behavior and Planning Mechanisms
}

\author{
Yaojie Li \\ Columbus State University \\ li_yaojie@columbusstate.e \\ $\underline{\mathrm{du}}$ \\ Xuan Wang \\ University of Texas Rio \\ Grande Valley \\ xuan.wang@utrgv.edu
}

\author{
Thomas Stafford \\ Louisiana Tech University \\ stafford@latech.edu
}

\author{
Hanieh Javadi Khasraghi \\ University of Delaware \\ hanieh@udel.edu
}

\begin{abstract}
This paper seeks to understand general user intentions toward engaging in green information technology (IT) behaviors, and in engaging with the consumer electronics lifecycle, which includes not only adoption and use, but also disposal. Based upon an extended planned behavior theoretical framework, our study suggests that what we call "eco-belief" among technology users can determine eco-attitude, subjective norms, and perceived behavioral controls related to the life cycle process, thus shaping green user behavior. Also, eco-knowledge appears to be important in changing user's attitudes and intentions to perform green behaviors. This study also revisited relevant green IT and green Information Systems (IS) literature and viewpoints while providing possible research directions based on its analysis results.
\end{abstract}

\section{Introduction}

Society enjoys continuing advances in the proliferation of consumer electronics for daily life, bringing both falling prices and rising performance. As advances proliferate, something must be done with the equipment that is replaced, and this raises issues of ecoefficiency, eco-equity, and eco-effectiveness in the execution of the steps of the life cycle process for information technology [20,54]. According to the most recent Global E-Waste Monitor's report, a record of 53.6 million metric tons of e-waste (which is discarded consumer electronics such as computers and mobile phones) were discarded on a global level in 2019 [23]. At the same time, only 17.4 percent of that e-waste content was formally collected and recycled. This may be attributed to a lack of consideration of the final, disposal, stage of the technology life cycle, wherein recycling and reclamation might take place. In this sense, "the elephant in the junk room" grows ever large as technology continues to ever more fully integrate into users' lives. Yet, notwithstanding, the life span of consumer electronics is becoming ever shorter.

Companies, governments, and societies are entrusted with roles and responsibilities regarding environmental issues [42]. But, even in view of this, the user's role in the concluding phases of the life cycle is underestimated, and their subsequent motivation to provide supportive input, at the same time, undermined.

User resources and talents can be efficiently organized in the concluding phases of the technology life cycle, thus addressing the conflict between environmental protection and the manufacture, promotion, and consumption of consumer electronics. Unfortunately, the issue appears to be that users are not engaging at this stage of the life cycle [23]. In addition to their limited individual influence and resources in organizational settings, end-users, in general, are recognized as passive performers in organizational green IT.

Put another way, users are the largest population in the most significant phases of the life-span of consumer electronics - purchase, use, and disposal. In the consumer-driven economy, the focus is on the audience of users. With pro-environmental attitudes on the part of end-users, even small gains in environmentally friendly use of technology across the life cycle can be accumulated and, in the end, exert tremendous influence. In like manner, if users choose to circumvent green information technology (IT) practices and routinely discard e-waste, the adverse effects can be magnified.

Also, another aspect of user involvement stems from the insights they gain in their daily interactions with technology. Such insights can be leveraged to address many subtle issues which are then solvable by technology vendors, e-waste disposers, and governmental entities. By way of example, one sort of insight might regard where and how to either purchase or sell a used technological device (green purchase), where another level of insights might lead to the knowledgeable development of power management functions on computers and smartphones (green use). Insights can also guide knowledge of the existence and locations of convenient locations for recycling discarded technological devices (green disposal). To that end, user experience and knowledge can leverage eco-efficiency and eco-effectiveness initiatives [19, 20, $35,54]$ smoothly.

Recent research interests have dealt with relatively fragmented green practices (green purchase, or green use, or green disposal); in contrast, however, there is a 
lack of research on holistic green user behaviors in the electronics' lifecycle. Both green purchase behaviors and green consumerism have been well examined in the marketing and consumer behavior literature $[9,11,30,32,33,37,43,56]$. In the information systems literature, research is mainly situated on the green IT use in organizational settings, focused on explaining the drivers and consequences of green IT adoption and use [6, 12, 38, 39].

Green disposal studies widely appear in the ecology literature, and their understanding can be applied to the growing e-waste problem. To that end, the primary purpose of this research is to explore systematic green practices in parallel with the phase of the technology life cycle in consumer electronics. In this, we will consider how users are engaged in the purchase, the use, and the eventual disposal of devices. It is also seen that most Green IT studies are conceptual work [7,17,48,54]. To that end, we fill this research gap through an in-depth investigation into user-oriented green behaviors while explaining the underlying motivation mechanism. Hence, this study aims to address two research questions: (1) what are the nature and characteristics of green user behavior in the consumer electronics lifecycle? and, (2) how and why will users become engaged in green IT practices as part of their daily life?

\section{Literature review and hypotheses development}

\subsection{Green IT, green IS, and green user behavior}

While the terms "green IT" and "green IS" have often been used interchangeably in the literature, they are conceptually different. The view of green IT rests on the assumption that the technology, itself, is the source of and the solution to environmental problems such as carbon emission and e-waste [42]. The more expansive green Information Systems (IS) perspective acknowledges the role that technology users have in the combined systemic entity. This perspective proposes that information systems, including the people and procedures that organize them, are an alternative solution to environmental problems $[16,17,50]$. Green Information Systems, subsuming both technological and human components, have been summarized in various ways in the literature. Murugesan [42], for example, characterizes the practice of designing, manufacturing, using, and disposing of computers and peripherals with minimal or no impact on the environment, and doing so effectively and efficiently. Watson and colleagues [54], early thought leaders on the topic, stressed the role that user beliefs in eco-efficiency, eco-equity, and eco- effectiveness play in green IS. In our work, we embrace both the practical and ideological meanings of green IS since our unit of analysis - IT users - can engage in many green practices while being motivated by diverse eco-beliefs and values. Therefore, we define green user electronics lifecycle behavior as:

\section{Individual behaviors, based on one's belief in eco-efficiency, effectiveness, and equity, which are pro-environmental as regards the purchase, use, and disposal of consumer electronics in daily life.}

Following Dedrick's conceptualization [17], we propose that users can at least participate in three important steps of the life-span of information technology - green purchase, green use, and green disposal. Each of these life cycle steps has been individually examined in the work of three different disciplines, respectively. First, the green purchase has been a focal topic in green marketing and consumer behavior literature.

Green consumerism provides a theoretical framework that illustrates an ethical consumer attitude toward protecting the natural environment [9, 37]. Relevant studies focus on factors that include consumers' ecological concerns, ecological awareness, and their purchasing preferences for eco-friendly products and services $[32,43,56]$. This work has also engaged with explaining consumer preference for patronizing ecoconscious organizations and entities [30,33].

The second component - green IT adoption and use - has been extensively studied in the Management Information Systems literature. A large number of studies have explored the antecedents and consequences of green IT adoption and use in organizational settings $[6,12,18,38,52]$. The IS literature has also touched on pro-environmental IT practice and user engagement [14,39].

The last component contained in our conceptualization of green user electronics lifecycle behavior is green disposal, corresponding to the concluding phase of the technology life cycle. Examinations of this topic appear in the environmental psychology literature, which has frequently focused on aspects of clean manufacturing and corporate operations $[13,21,47,53]$. Based on the separate streams of green user behaviors corresponding to the different phases of the technology life cycle, we argue that users can engage in each or any of these pro-environmental behaviors, even if the situational context of their engagement renders them as utilizing consumers or engaged environmentalists in different settings. 


\subsection{An extended theory of planned behavior in the green IS context}

As we look into the planning and motivation mechanisms of green user behavior across the technology life cycle, we believe that the theory of planned behavior can be effectively leveraged for insights. The theory has already been widely applied in the relevant green consumer behavior research in the cause of identifying antecedents of green purchase intentions $[27,45,33,55,56]$.

The theory of planned behavior (TPB) [3] was developed from the theory of reasoned action, TRA, from Fishbein \& Ajzen [22]. It was considered that TPB corrected a flaw in TRA by dealing with significant confound risks between attitudes toward the decision object and the influence of subjective norms in the decision calculus. The concern has been that one could be reframed into the other. TPB also incorporates a nonvolitional factor in the form of perceived behavioral control. With respect to green IT practices, one considers external constraints such as limited resources (e.g., affordability of green electronics with higher price), the cost of time and effort (e.g., reusing and recycling electronics rather than simply discarding them), and pertinent environmental factors such as availability and locations of recycling facilities. We perceive advantages in TPB over similar frameworks, for the purposes of our study.

Figure 1. Theory of planned behavior (TPB) (adopted from Ajzen, 1991)

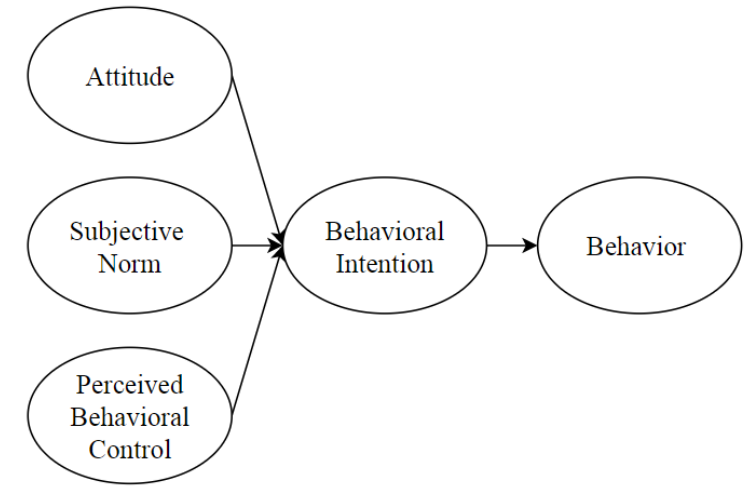

According to TPB, factors of attitude, subjective norms, and perceived behavioral control come together to shape individual behavioral intentions and behaviors towards some consumer decision (see Figure 1). Attitude refers to "the degree to which a person has a favorable or unfavorable evaluation of the behavior in question" [3]. Eco-attitude - the user's judgment on green practices - will determine if he or she would engage environmentally friendly technological practices, and would be a combinatorial function of these antecedents to attitudes defined in TPB. Ramayah et al. [46] suggest the consideration of linkages between perceived consequences and intended behavior. Paul and colleagues [45], however, indicate that attitude is the main predictor of the behavioral intention of green purchase. Thus, we propose that:

H1: Eco-attitude is positively associated with the intention to engage in green user electronics lifecycle behavior.

In the TPB framework, the influence of subjective norms about the worth of a certain activity is a key determinant of the subsequent behavioral intention to engage in such activities. It can be defined as the perceived social pressure to perform or not to perform a given behavior [3]. Social influences can come from sources such as family, friends, colleagues, and other closely-related social members. Subjective norms capture one's perceptions of the social pressures associated with any given green behavior. The important norms can both overtly and covertly influence individual green behavioral intentions. For example, one may easily follow family or friends' suggestion sin choosing an energy-saving computer, or identifying a computer with pro-environmental design and technologies. Subjective norms certainly impact purchase decisions, but they also impact disposal decisions, as well, if the user wants to be a part of a community or micro-society which favors green IT practices. Therefore, we hypothesize:

H2: Subjective norm is positively associated with the intention of green user electronics lifecycle behavior.

Another salient factor in TPB is the aspect of the users' perceived behavioral control. Perceived behavioral control refers to the perceived ease or difficulty of performing a given behavior [3]. According to Ajzen [4], perceived behavioral control represents the concept of resources; this implies the role of facilitating factors and action control [51]. Comparing attitude and subjective norms with internal factors, we see that perceived behavioral control largely revolves around the influence of external factors. As noted, users have to overcome environmental constraints while participating in green IT practices. Hence, we propose that:

H3: Perceived behavioral control is positively associated with the intention of green user electronics lifecycle behavior.

As we bridge the Theory of Planned Behavior with the concept of eco-belief in the green IS literature, we look to the different sorts of external factors that play a role. Ajzen and Fishbein [22] suggested three categories of external beliefs (attitudinal, normative, and control) as the antecedents of attitude, subjective norm, and 
perceived behavioral control, respectively. Drawing from Coleman's [15] micro-macro model that proposes how organizational and social sustainability contexts influence organizational and individual beliefs about the environment and their subsequent sustainable activities, Melville [36] conceptualized the TPB belief-actionoutcome framework in an IS context. This framework postulates that social and organizational structures can impact individual beliefs about the environment, which, in turn, can be interpreted through user engagement in sustainable actions and eventual environmental and economic outcomes. More specifically, Watson and colleagues [54] classified two eco-beliefs: ecoefficiency and eco-equity, based on their research. Ecoefficiency is related to the delivery of competitivepriced goods and services that satisfy human needs while progressively reducing adverse ecological effects, in line with the earth's carry capacity [19]. Eco-equity refers to "equity between peoples and generations and particularly the equal rights of all peoples to environment resources [26].

Taken together, this group of conceptual green IS studies direct our conjecture about the relationships between eco-beliefs and three perceived behavioral control antecedents to the intention of engaging in green user technology behavior. The eco-beliefs are likely to shape the attitude towards green IT practice, promote norms and cultures in support of pro-environmental activities, and increase one's perceived behavioral control while facing problems that can hinder their green behavior intention. Thus, the following were hypothesized:

H4a: Eco-beliefs are positively associated with eco-attitudes.

H4b: Eco-beliefs are positively associated with subjective norms about green IS.

H4c: Eco-beliefs are positively associated with perceived behavioral control of green technologies and their life cycle.

Chan and Lau [11] define environmental knowledge as an individual's understanding of environmental issues. Fryxell and Lo [25] further define environmental knowledge as one's understanding of the environment, significant relationships with environmental impact, and people's responsibilities for sustainable development. Mostafa [40] resonated with Fryxell and Lo's definition [25] while accentuating knowledge about core relationships that may exert influence on environmental surroundings. When people are concerned with environmental issues, environmental knowledge can adjust their attitude and intentions to behave pro-environmentally $[49,55]$. In the context of green IS, users likewise could change their attitude and intention to practice green IS as they acquire adequate ecological knowledge. This consideration leads to the following hypotheses:

H5a: Eco-knowledge is positively associated with eco-attitudes.

H5b: Eco-knowledge is positively associated with the intention of engaging in green user electronics lifecycle behavior.

\section{Research methodology}

\subsection{Qualitative inquiry with focus groups}

To accomplish the research objective, we operationalize the constructs and measurement items by conducting focus groups with general IT users as well as through the adoption of measures from relevant literature. As discussed, our study distinguishes itself from prior studies through the integration of fragmented green user behaviors (i.e., green purchase, green use, and green disposal) into the broader context of the consumer electronics life cycle [23]. As depicted in Figure 2, green users, green consumers, or green activities can contribute to various phases of the IT product lifecycle, including design and manufacturing, marketing and sales, purchasing and use, and final stage collection, recycling, and disposal. To confirm our conjecture and to evaluate the measurement items adopted from prior studies, we initiated a qualitative inquiry into green user behavior with 11 focus groups comprised of 41 students and Information Systems/Computer Science faculty from a southeastern university in the U.S. We adopted a semi-structured discussion approach and asked questions revolving around 1) life examples about green user behaviors, 2) ecological knowledge and beliefs (rarely examined in the IS literature) and 3) motivational mechanisms for green user behaviors. Most comments and viewpoints from this examination are consistent with the green IT/IS literature and our hypothetical expectations derived from it. Even so, a few novel ideas and concepts emerged in the focus group discussions; these included virtualization and cloud computing as alternative methods of reducing e-waste. These considerations have been incorporated into our measurement model, as demonstrated in the Appendix. 
Figure 2. Green user behavior in the electronics lifecycle

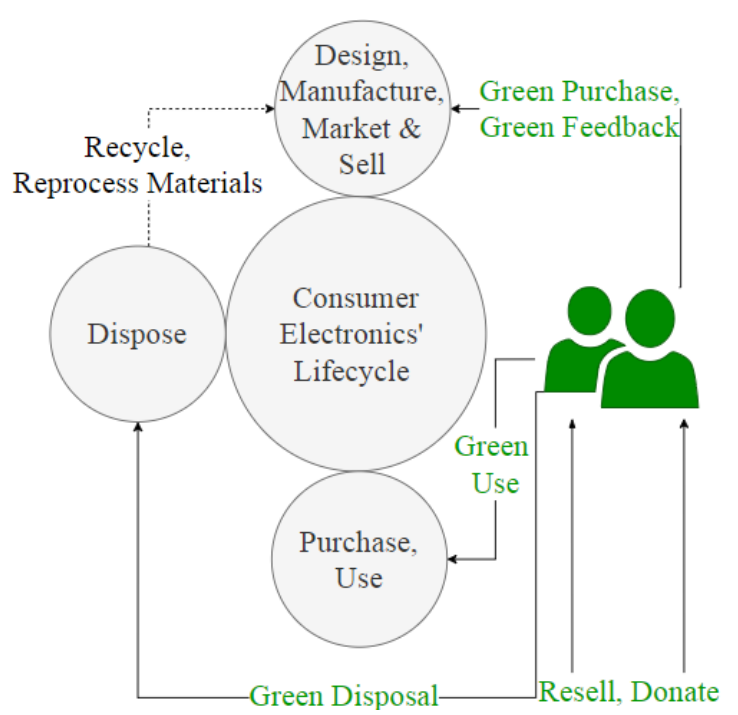

\subsection{Survey setting and participants}

We collected primary data through a field survey from five American universities of various sizes and backgrounds. Since college faculty and students generally have access to computers and similar electronic devices, we believe this sample fits our goal of investigating the motivation mechanism of green user electronics lifecycle behavior. The participants were mainly a mixture of undergraduate and graduate college students who participated in exchange for extra course credit. The demographics and IT-relevant descriptive statistics are illustrated in Table 1 . We received a total of 394 responses, of which 247 valid responses remained after data screening, including removing inattentive and incomplete responses and extreme outliers.

\subsection{Measurement development}

The measurement items were adapted from key studies in our literature review and focus group discussions. Preliminary analysis was undertaken to assess basic psychometric properties, and the most reliable measures were then retained for fitting the hypothesized model. In this study, there are six constructs, including eco-belief with seven indicators, eco-attitude with five indicators, the subjective norm with three indicators, eco-knowledge with seven indicators, perceived behavioral control with five indicators and intention to engage in green user electronics lifecycle behavior with seven indicators (Appendix).

\subsection{Exploratory factor analysis}

An exploratory factor analysis was conducted to explore the factor structure of constructs while reducing cross-loading items. Principal component analysis with varimax rotation was applied to identify variables highly associated with the constructs in the model. Through the factor analysis, we identified 34 items characterized by factor loadings above a threshold value of 0.4. Table 2 illustrates an excessive degree of consistency among the items under each factor with their respective factorloadings. After completing the factor analysis, we retained 29 measurement items for further use in the study, and the factor scores obtained from the analysis were retained for purposes of hypothesis testing. The exogenous constructs of the study were eco-belief and eco-knowledge; the endogenous constructs al regarded various assessments of subsequent intentions to perform green user electronics lifecycle behaviors.

\subsection{Reliability and validity}

Reliability and validity are the primary focus in studies employing structural equational modeling [28]. According to Nunnally [44], reliability levels beyond 0.7 form a threshold to ensure that results are reasonably free of measurement error and will perform in a reliable manner. In our analysis, construct reliability scores across the overall study exceed 0.7. However, we also assessed reliability as part of investigating the trait validity features of convergence and discrimination in our construct validation process [7]. Table 3 shows that the model fits the data well, since composite reliability scores on constructs, as well as Cronbach's alphas scores for individual scales, are all greater than 0.7 . The average variances extracted (AVE) values were also round to be greater than the square of the individual correlations among constructs. Therefore, we obtain sound evidence in support of convergent and discriminant validity among the reflective constructs in the model.

Table 3. Construct reliability and validity

\begin{tabular}{llll}
\hline Component & $\begin{array}{l}\text { Composite } \\
\text { Reliability }\end{array}$ & $\begin{array}{l}\text { Cronbach's } \\
\text { Alpha }\end{array}$ & AVE \\
\hline Eco-Belief & 0.910 & 0.885 & 0.593 \\
$\begin{array}{l}\text { Eco-Attitude } \\
\text { Subjective }\end{array}$ & 0.889 & 0.844 & 0.617 \\
$\begin{array}{l}\text { Norm } \\
\text { Perceived }\end{array}$ & 0.931 & 0.888 & 0.819 \\
$\begin{array}{l}\text { Control } \\
\text { Eco-Knowledge }\end{array}$ & 0.875 & 0.777 & 0.693 \\
$\begin{array}{l}\text { Intention to } \\
\text { Green IT }\end{array}$ & 0.937 & 0.817 & 0.591 \\
\hline
\end{tabular}




\section{Analysis results}

Hypothesis testing results for all the constructs in the model are shown in Figure 3. In this study, PLSSEM assessment of the path model was used. As shown, significant effects, supportive of hypothesized expectations, are found for all paths.

In consideration of the antecedents to green user electronics lifecycle behaviors, Hypotheses 1, 2, and 3, which are based on the Theory of Planned Behavior, are wholly supported in terms of positive and significant relationships. In other words, eco-attitudes, subjective norms, and perceived behavioral control are all good determinants of user intentions to engage in the green purchase, green use, and green disposal. The hypotheses related to eco-belief and its three antecedents are also supported. Our results here are supportive of the conceptual propositions found in the early work of green IS. Our study also reveals significant and positive relationships between eco-knowledge and eco-attitude and the subsequent intention to perform green user behaviors in the electronics lifecycle, respectively.

\section{Discussion and implications}

Our results suggest that IT users' intentions to perform green behaviors, can be predicted by ecoattitudes, subjective norms, and perceived behavioral control, as well as by eco-knowledge. Also, we found that eco-beliefs play a significant role in determining eco-attitude, subjective norms, and perceived behavioral control. In the lens of an extended Theory of Planned Behavior, our findings are consistent with a number of green consumer behaviors $[29,30,33,45,55$, 56] while extending the boundaries of green technology behaviors beyond the mere purchase act to include subsequent technology use and technology disposal, as well.

Despite significant results in support of the motivational mechanisms posited for green technology user behaviors, several limitations exist and provide possible opportunities for future research. First, this study is limited in its potential generality by the use of a convenience sample; students and faculty, being welleducated and knowledgeable, are more prone to socially desirable responses [31]. The threat of self-selection bias could also be considered if respondents are considered to be mainly pro-environmental technology users. As such, future studies may focus more on the identification of broader and general samples and to including more diverse participants.

There is also the consideration that the construct of eco-belief could be multi-dimensional. As Watson et al. suggested [54], eco-effectiveness can contain ecoefficiency and eco-equity. While our factor analysis indicates a strong interrelation between the two, further investigation is warranted.

Here, we strictly follow the conventional explications of the Theory of Planned Behavior, and in doing so, we utilize many existing conventional measurement items. Even if our analysis successfully supports the propriety of planning mechanisms in directing technology user's green behaviors, we recognize the danger of a reductionistic perspective and are reluctant to attempt alternative explanations, beyond those supported by our results.

We think that in-depth qualitative studies can unveil new perspectives of green IS that intertwine with the lifecycle of consumer electronics. More importantly, emerging concepts and theories can be found, thus expanding the boundaries of green IS research, going forward.

Despite the opportunities for future research, the practical implications of our work here are evident, we believe. First, the planning mechanism we examined can be utilized in promoting green user electronics lifecycle behavior in a wide variety of settings ranging from the workplace to the social place. Secondly, educating technology users with adequate eco-knowledge is necessary, too.

\section{Conclusion}

IT-relevant environmental and sustainability issues cause increasing concerns and challenges to many people and organizations. There has largely been no efficient manner devised to address these "trivial" but important green problems, such as consuming short lifespan electronics and randomly discarding e-waste. To that end, we articulate the essential role of general technology users, on the general principle that those who are involved in the production of a problem with green IS are also able to contribute to the solution. By examining these perceptions, the well-established framework of the Theory of Planned Behavior, study suggests that eco-belief and eco-knowledge are both important drivers in promoting green user electronics lifecycle behavior in the purchase, use, and disposal of technological products. 
Figure 3. Structural model of green user behavior in the electronics lifecycle

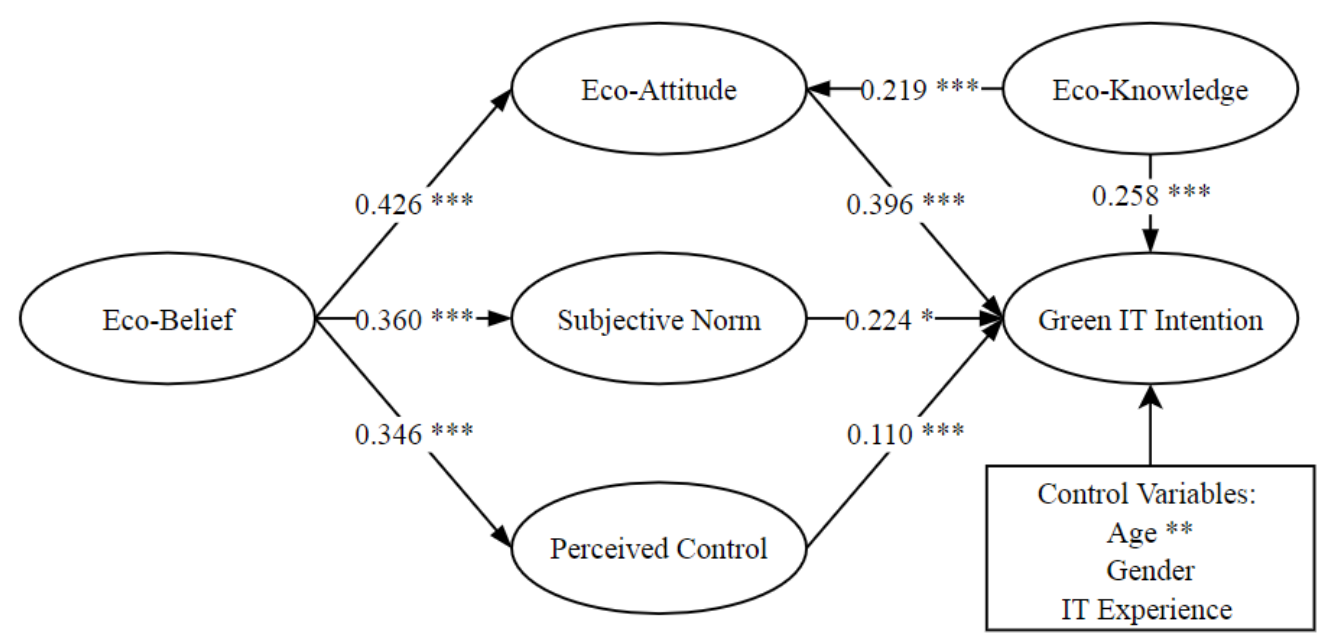

Note. $* p<0.1 ; * * p<0.05, * * * p<0.01$.

Table 1. Demographics of respondents

\begin{tabular}{lllllll}
\hline Gender & Age & Education & $\begin{array}{l}\text { Work } \\
\text { experience }\end{array}$ & $\begin{array}{l}\text { IT use } \\
\text { experience }\end{array}$ & $\begin{array}{l}\text { Replacement } \\
\text { frequency (yr.) }\end{array}$ & IT proficiency \\
\hline Male & 20 \& below & Some coll. credit & Range & Range & Range & Fundamental \\
$112(45.34 \%)$ & $110(41.53 \%)$ & $153(61.94 \%)$ & $0-40$ & $2-40$ & $0-10$ & $50(20.24 \%)$ \\
Female & $21-30$ & Associate degree & Mean & Mean & Mean & Novice \\
$135(54.66 \%)$ & $115(46.56 \%)$ & $34(13.77 \%)$ & 4.86 & 12.35 & 4.60 & $64(25.91 \%)$ \\
& $31-40$ & Bachelor's degree & Std. Dev. & Std. Dev. & Std. Dev. & Intermediate \\
& $16(6.48 \%)$ & $48(19.43 \%)$ & 6.15 & 5.81 & 1.60 & $107(43.32 \%)$ \\
& $41 \&$ above & Master's degree & & & & Advanced \\
& $6(2.43 \%)$ & $8(3.24 \%)$ & & & & Expert \\
& & Doctoral degree & & & & $1(0.40 \%)$ \\
\hline
\end{tabular}

Table 2. Finalized indicator loadings

\begin{tabular}{lccccccc}
\hline \multicolumn{7}{c}{ Component } \\
\hline Eco-Belief & 1 & 2 & 3 & 4 & 5 & 6 & 7 \\
Eco-Attitude & 0.831 & 0.819 & 0.770 & 0.722 & 0.712 & 0.648 & 0.593 \\
Subjective Norm & 0.724 & 0.678 & 0.646 & 0.627 & 0.607 & & \\
Perceived Control & 0.799 & 0.769 & 0.710 & & & & \\
Eco-Knowledge & 0.855 & 0.802 & 0.547 & & & & \\
Green IT Intention & 0.822 & 0.805 & 0.726 & 0.587 & 0.443 & & \\
\hline
\end{tabular}




\section{References}

[1] A.B. Smith, C.D. Jones, and E.F. Roberts, "Article Title", Journal, Publisher, Location, Date, pp. 1-10.

[2] Jones, C.D., A.B. Smith, and E.F. Roberts, Book Title, Publisher, Location, Date.

[3] Ajzen, I. (1985). From intentions to actions: A theory of planned behavior. In Action control (pp. 11-39). Springer, Berlin, Heidelberg.

[4] Ajzen, I. (1989). Attitude structure and behavior. Attitude structure and function, 241, 274.

[5] Ajzen, I. (1991). The theory of planned behavior. Organizational behavior and human decision processes, 50(2), 179-211.

[6] Bose, R., \& Luo, X. (2011). Integrative framework for assessing firms' potential to undertake Green IT initiatives via virtualization-A theoretical perspective. The Journal of Strategic Information Systems, 20(1), 38-54.

[7] Boudreau, M. C., Chen, A., \& Huber, M. (2008). Green IS: Building sustainable business practices. Information systems: A global text, 1-17.

[8] Boudreau, M. C., Gefen, D., \& Straub, D. W. (2001). Validation in information systems research: A state-ofthe-art assessment. MIS quarterly, 1-16.

[9] Carrington, M. J., Neville, B. A., \& Whitwell, G. J. (2010). Why ethical consumers don't walk their talk: Towards a framework for understanding the gap between the ethical purchase intentions and actual buying behaviour of ethically-minded consumers. Journal of Business Ethics, 97(1), 139-158.

[10] Chan, R. Y., \& Lau, L. B. (2000). Antecedents of green purchases: a survey in China. Journal of consumer marketing.

[11] Chan, R. Y., \& Lau, L. B. (2002). Explaining green purchasing behavior: A cross-cultural study on American and Chinese consumers. Journal of International Consumer Marketing, 14(2-3), 9-40.

[12] Chen, A. J., Watson, R. T., Boudreau, M. C., \& Karahanna, E. (2011). An institutional perspective on the adoption of Green IS \& IT. Australasian Journal of Information Systems, 17(1).

[13] Chi, X., Wang, M. Y., \& Reuter, M. A. (2014). E-waste collection channels and household recycling behaviors in Taizhou of China. Journal of Cleaner Production, 80, 87-95.

[14] Chow, W. S., \& Chen, Y. (2009). Intended belief and actual behavior in green computing in Hong Kong. Journal of Computer Information Systems, 50(2), 136-141.

[15] Coleman, J. S. (1986). Social theory, social research, and a theory of action. American Journal of Sociology, 91(6), 1309-1335.

[16] Davenport, T., \& Linder, J. (1994). Information Management Infrastructure: the new competitive weapon? In HICSS (4) (pp. 885-896).

[17] Dedrick, J. (2010). Green IS: concepts and issues for information systems research. Communications of the Association for Information Systems, 27(1), 11.
[18] Deng, Q., \& Ji, S. (2015). Organizational green IT adoption: concept and evidence. Sustainability, 7(12), 16737-16755.

[19] DeSimone, L. D., \& Popoff, F. (1997). Eco-efficiency; The Business Link to Sustainable Development, MIT Press, Cambridge.

[20] Dyllick, T., \& Hockerts, K. (2002). Beyond the business case for corporate sustainability. Business strategy and the environment, 11(2), 130-141.

[21] Echegaray, F., \& Hansstein, F. V. (2017). Assessing the intention-behavior gap in electronic waste recycling: the case of Brazil. Journal of Cleaner Production, 142, 180-190.

[22] Fishbein, M., \& Ajzen, I. (1977). Belief, attitude, intention, and behavior: An introduction to theory and research.

[23] Forti, V., Baldé, C. P., Kuehr, R., \& Bel, G. (2020) The Global E-Waste Monitor 2020: Quantities, Flows, and the Circular Economy Potential.

[24] Francoeur, V., Paillé, P., Yuriev, A., \& Boiral, O. (2019). The measurement of green workplace behaviors: A systematic review. Organization \& Environment, 1-25.

[25] Fryxell, G. E., \& Lo, C. W. (2003). The influence of environmental knowledge and values on managerial behaviours on behalf of the environment: An empirical examination of managers in China. Journal of business ethics, 46(1), 45-69.

[26] Gray, R., \& Bebbington, J. (2000). Environmental accounting, managerialism, and sustainability: Is the planet safe in the hands of business and accounting? Advances in Environmental Accounting \& Management, 1. Management, 1, 1-44.

[27] Ha, H. Y., \& Janda, S. (2012). Predicting consumer intentions to purchase energy-efficient products. Journal of Consumer Marketing.

[28] Hair, J. F., Black, W. C., Babin, B. J., Anderson, R. E., \& Tatham, R. L. (1998). Multivariate data analysis (Vol. 5, No. 3, pp. 207-219). Upper Saddle River, NJ: Prentice Hall.

[29] Han, H. (2015). Travelers' pro-environmental behavior in a green lodging context: Converging value-beliefnorm theory and the theory of planned behavior. Tourism Management, 47, 164-177.

[30] Han, H., \& Kim, Y. (2010). An investigation of green hotel customers' decision formation: Developing an extended model of the theory of planned behavior. International Journal of Hospitality Management, 29(4), 659-668.'

[31] Kaiser, F. G., Schultz, P. W., Berenguer, J., CorralVerdugo, V., \& Tankha, G. (2008). Extending planned environmentalism: Anticipated guilt and embarrassment across cultures. European Psychologist, 13(4), 288-297.

[32] Kim, H. Y., \& Chung, J. E. (2011). Consumer purchase intention for organic personal care products. Journal of Consumer Marketing.

[33] Kim, Y. J., Njite, D., \& Hancer, M. (201). Anticipated emotion in consumers' intentions to select eco-friendly restaurants: Augmenting the theory of planned 
behavior. International Journal of Hospitality Management, 34, 255-262.

[34] McCarty, J. A., \& Shrum, L. J. (1994). The recycling of solid wastes: Personal values, value orientations, and attitudes about recycling as antecedents of recycling behavior. Journal of Business Research, 30(1), 53-62.

[35] McDonough, W., \& Braungart, M. (1998). The next industrial revolution. The Atlantic Monthly, 282(4).

[36] Melville, N. P. (2010). Information systems innovation for environmental sustainability. MIS Quarterly, 34(1), $1-21$.

[37] Moisander, J. (2007). Motivational complexity of green consumerism. International Journal of Consumer Studies, 31(4), 404-409.

[38] Molla, A., \& Abareshi, A. (2012). Organizational green motivations for information technology: an empirical study. Journal of Computer Information Systems, 52(3), 92-102.

[39] Molla, A., Abareshi, A., \& Cooper, V. (2014). Green IT beliefs and pro-environmental IT practices among IT professionals. Information Technology \& People.

[40] Mostafa, M. M. (2007). Gender differences in Egyptian consumers' green purchase behaviour: the effects of environmental knowledge, concern, and attitude. International Journal of Consumer Studies, 31(3), 220-229.

[41] Moore, G. (1965). Moore's law. Electronics Magazine, 38(8), 114 - 118.

[42] Murugesan, S. (2008). Harnessing green IT: Principles and practices. IT professional, 10(1), 24-33.

[43] Nimse, P., Vijayan, A., Kumar, A., \& Varadarajan, C. (2007). A review of green product databases. Environmental Progress, 26(2), 131-137.

[44] Nunnally, J. C. (1994). Psychometric theory 3E. Tata McGraw-hill education.

[45] Paul, J., Modi, A., \& Patel, J. (2016). Predicting green product consumption using theory of planned behavior and reasoned action. Journal of Retailing and Consumer Services, 29, 123-134.

[46] Ramayah, T., Lee, J. W. C., \& Mohamad, O. (2010). Green product purchase intention: Some insights from a developing country. Resources, conservation and recycling, 54(12), 1419-1427.

[47] Saphores, J. D. M., Ogunseitan, O. A., \& Shapiro, A. A. (2012). Willingness to engage in a pro-environmental behavior: An analysis of e-waste recycling based on a national survey of US households. Resources, Conservation and Recycling, 60, 49-63.

[48] Sarkis, J., Koo, C., \& Watson, R. T. (2013). Green information systems \& technologies-this generation and beyond: Introduction to the special issue. Information Systems Frontiers, 15(5), 695-704.

[49] Scott, L., \& Vigar-Ellis, D. (2014). Consumer understanding, perceptions and behaviours with regard to environmentally friendly packaging in a developing nation. International journal of consumer studies, 38(6), 642-649.

[50] Silver, M. S., Markus, M. L., \& Beath, C. M. (1995). The information technology interaction model: A foundation for the MBA core course. MIS Quarterly, 361-390.

[51] Triandis, H. C. (1977). Interpersonal behavior. Brooks/Cole Pub. Co.

[52] Thomas, M., Costa, D., \& Oliveira, T. (2016). Assessing the role of IT-enabled process virtualization on green IT adoption. Information Systems Frontiers, 18(4), 693-710.

[53] Wang, Z., Zhang, B., Yin, J., \& Zhang, X. (2011). Willingness and behavior towards e-waste recycling for residents in Beijing city, China. Journal of Cleaner Production, 19(9-10), 977-984.

[54] Watson, R. T., Boudreau, M. C., \& Chen, A. J. (2010). Information systems and environmentally sustainable development: energy informatics and new directions for the IS community. MIS Quarterly, 23-38.

[55] Yadav, R., \& Pathak, G. S. (2016). Young consumers' intention towards buying green products in a developing nation: Extending the theory of planned behavior. Journal of Cleaner Production, 135, 732-739.

[56] Yadav, R., \& Pathak, G. S. (2017). Determinants of consumers' green purchase behavior in a developing nation: Applying and extending the theory of planned behavior. Ecological Economics, 134, 114-122. 


\section{Appendix. Constructs and measurement items}

Constructs and measurement items
Eco-belief
EB1: I believe that green user behaviors contribute to the efficient use of environmental resources.
EB2: I believe that reducing energy consumption by digital devices minimizes greenhouse gas
emissions.
EB3: I believe that green user behaviors benefit limited environmental resources.
EB4: I believe green user behaviors reduce adverse ecological effects.
EB5: I believe that green user behaviors promote a fair distribution of environmental resources within
all peoples.
EB6: I believe that green user behaviors promote a fair distribution of environmental resources across
generations.
EB7: I believe that green user behaviors conserve the resources for everyone.

References

DeSimone et al. [19]; Molla et al. 39]; McCarty \& Shrum [36]; Murugesan [42]; Watson et al. [54]

\section{Attitude toward green user behavior}

AT1: I have a favorable attitude toward the green purchase, green use, and green disposal.

AT2: I would like to choose digital devices with green features such as power management.

AT3: People should be concerned about controlling the power consumption of digital devices.

AT4: I like the idea of reusing, refurbishing, and recycling digital devices.

AT5: Green user behaviors are pleasant.

Subjective norm

SN1: Most people who are important to me think I should choose green digital devices.

SN2: Most people who are important to me think I should use green digital devices.

SN3: Most people who are important to me think I should dispose of digital devices in a pro-

environmental way.

\section{Perceived behavioral control}

PC1: It is entirely up to me to choose green digital devices at the place of the conventional non-green ones.

PC2: I feel that using green digital services is entirely within my control.

PC3: I have resources, time, and opportunities to choose green digital devices and services.

Molla et al. [39];

Murugesan [42];

Paul et al. [45]

Chan \& Lau [11]; Paul et al. [45]

McCarty \& Shrum [36]; Han \& Kim [30]

Mostafa [40]

Eco-knowledge

EK1: I know how to enable power management features on my computer.

EK2: I am very knowledgeable about environmental issues.

EK3: I know how to reduce energy consumption while using digital devices.

EK4: I know how to recycle digital devices in the right way.

EK5: I know where I can recycle unwanted digital devices.

Intention to green user behavior in the electronics lifecycle

IT1: I intend to use eco-friendly digital devices.

IT2: I intend to use eco-friendly digital services, such as cloud computing and virtualization.

IT3: I intend to apply the power management features of digital devices I regularly use.

IT4: I intend to recycle digital devices.

IT5: I intend to persuade others to dispose of digital devices pro-environmentally.

IT6: I intend to choose environmental-friendly brands for ecological reasons.

Francoeur et al. [24]; Molla et al. [39] 